Service Elements of Bus Rapid Transit

\title{
The Importance Customers Place on Specific Service Elements of Bus Rapid Transit
}

\author{
Michael R. Baltes \\ National Bus Rapid Transit Institute
}

\begin{abstract}
Bus Rapid Transit (BRT) is a rapidly growing national trend in the provision of public transportation. At present, with more than 150 New Start Rail Projects currently in the FTA pipeline, a wide range of alternatives is necessary to fulfill the demand for cost-effective rapid public transportation. As a lower cost, high-capacity mode of public transportation, BRT can serve as an option to help address the growing traffic congestion and mobility problems in both urban and nonurban areas. Careful documentation and analyses of BRT systems and the unique features of these projects will help determine the most effective features offered by the BRT systems such the most successful service characteristics, level of transit demand, region size, and other amenities. This article presents a statistical analysis of the data from two on-board customer surveys conducted in 2001 of the BRT systems in Miami and Orlando, Florida. Using data from the two on-board surveys, the simplest method for measuring the importance that customers place on specific BRT service characteristics is to calculate mean scores for each characteristic using some type of numeric scale (e.g., a scale of 1 through 5, with 5 being the highest). While there are no real discernable drawbacks to this simple method, an alternate technique to measure the importance of each service attribute is to derive the importance of each attribute using STEPWISE regression. This statistical method estimates the importance of each
\end{abstract}


attribute to overall customer satisfaction. The results indicate that customers place a high value on the BRT service characteristics frequency of service, comfort, travel time, and reliability of service.

\section{Introduction}

One of the main goals of the Federal Transit Administration's (FTA) Bus Rapid Transit (BRT) Demonstration Program is to determine the effects of 10 nationwide BRT demonstration projects through a scientific evaluation process. The FTA designated the South Miami-Dade Busway, Busway for short, as one of its 10 BRT demonstration sites. While not one of FTA's 10 designated BRT demonstration projects, the Lynx LYMMO in Orlando was chosen by the FTA for evaluation due to its Intelligent Transportation Systems (ITS) and as a model for the implementation of similar BRT systems. According to the FTA, careful documentation and analyses of the BRT demonstration projects and the unique features of these projects will help determine the most effective features (i.e., type of service offered, most successful service characteristics, level of transit demand, region size, and other amenities). It is anticipated that the BRT demonstration projects will serve as learning tools and as models for other locales throughout the country, and possibly the world. For these demonstrations to have maximum effectiveness in their respective operational capacities, a consistent and carefully structured approach to project evaluation is necessary.

The following, taken verbatim from Evaluation Guidelines for Bus Rapid Transit Demonstration Projects (Schwenk 2001), are the four evaluation guidelines for the 10 BRT demonstration projects:

1. Determine the benefits, costs, and other impacts of individual BRT features, including ITS/APTS applications, and of the system as a whole.

2. Characterize successful and unsuccessful aspects of the demonstration.

3. Evaluate the demonstration's achievement of FTA and agency goals.

4. Assess the applicability of the demonstration results to other sites.

In addition, the FTA plans to examine specific impacts of the BRT demonstration projects. These impacts include: degree that bus speeds and schedule adherence improve; degree that ridership increases (due to improved bus speeds, schedule adherence, and convenience); effect of BRT on other traffic; effect of each of the BRT components on bus speed and other traffic; benefits of ITS/APTS applications to the demonstration project; and effect of BRT on land use and develop- 
ment. To meet these objectives, it is necessary to collect a variety of data on several aspects of the BRT demonstration project, including measurable impacts to BRT customers via the on-board survey process.

In keeping with the FTA's evaluation guidelines, the National Bus Rapid Transit Institute at the Center for Urban Transportation Research (CUTR), working jointly with Miami-Dade Transit (MDT) and Lynx, conducted on-board surveys of South Miami-Dade Busway customers in March 2001 and Lynx LYMMO customers in December 2001. The South Miami-Dade Busway and Lynx LYMMO are examples of different applications of BRT systems that are specifically designed to offer faster travel choices to customers compared to standard local bus service and possibly, even the private automobile. Evaluation of the various components of the Busway and LYMMO are crucial parts of the demonstration project. The two on-board surveys serve as the first phase of the independent review of the Busway and LYMMO BRT systems. The second phase will include analyses of the more detailed components of each BRT system, including engineering and construction, technical documentation, ITS, and system performance.

The on-board surveys were conducted to assess customer perceptions, behavior, and to develop customer profiles. The survey instruments asked customers to evaluate the various BRT elements of service as well as overall satisfaction, with the ultimate purpose of measuring the impacts of the systems on customer perceptions. Other questions focused on customer behavior, including trip origins and destinations and frequency of use.

\section{Objective}

This article presents a statistical analysis of the data from two on-board customer surveys of the BRT systems in Miami and Orlando, Florida. Using data from the two on-board surveys, the simplest method for measuring the importance that customers place on specific BRT service characteristics is to calculate mean scores for each characteristic using some type of numeric scale (e.g., a scale of 1 through 5 , with 5 being the highest). While there are no real discernable drawbacks to this simple averaging method, an alternate technique to measure the importance of each service attribute is to derive the importance of each attribute to overall satisfaction using more advanced statistical procedures such as STEPWISE regression. This statistical method estimates the importance of each service attribute to overall customer satisfaction. While there may be a degree of intercorrelation between each of the service attributes, this method can be used to measure the relative 
importance of each attribute when determining what elements or combination of elements best comprise overall customer satisfaction with these two BRT systems.

\section{South Miami-Dade and Orlando LYMMO BRT Systems}

\section{South Miami-Dade Busway}

The South Miami-Dade Busway, or Busway for short, is an 8-mile, two-lane busonly roadway constructed in a former rail right-of-way (the former Florida East Coast Railroad corridor) adjacent to US 1, a major north-south arterial in southern Miami-Dade County. Miami-Dade Transit (MDT) opened the first phase of the Busway on February 3, 1997. The Busway was designed for exclusive use by transit buses and emergency and security vehicles. The purpose of the Busway service is to address the need for faster travel choices for MDT customers. Much of the Busway BRT service uses 20-seat minibuses to keep costs to a minimum.

Currently, there are 18 intersections and 15 stations in each direction (30 total stations), as shown in Figure 1. The Busway corridor over much of its length is within 100 feet of the west side of US 1, one of the most heavily traveled corridors in Miami-Dade County. There are several types of service in the Busway corridor:

Local-Only operates on the exclusive Busway and makes every stop at all times (referred to as the Busway Local).

Limited Stop-Operates along the length of the Busway and beyond, skips stops nearest the Metrorail station during peak periods (Busway MAX or Metro Area Express).

Feeder-Collects passengers in neighborhoods and then enters the Busway at a middle point (service is known as either the Coral Reef MAX or Saga Bay MAX).

Crosstown-Preexisting routes in the corridor that now take advantage of the Busway when possible. These routes enter and exit the Busway at middle points. These routes are designed to provide access to many destinations in the region, not just to the center city (Routes 1, 52, and 65).

Intersecting-Routes in the corridor that intersect with Busway routes, sometimes stopping at Busway stations. 
Figure 1. Map of South Miami-Dade Busway

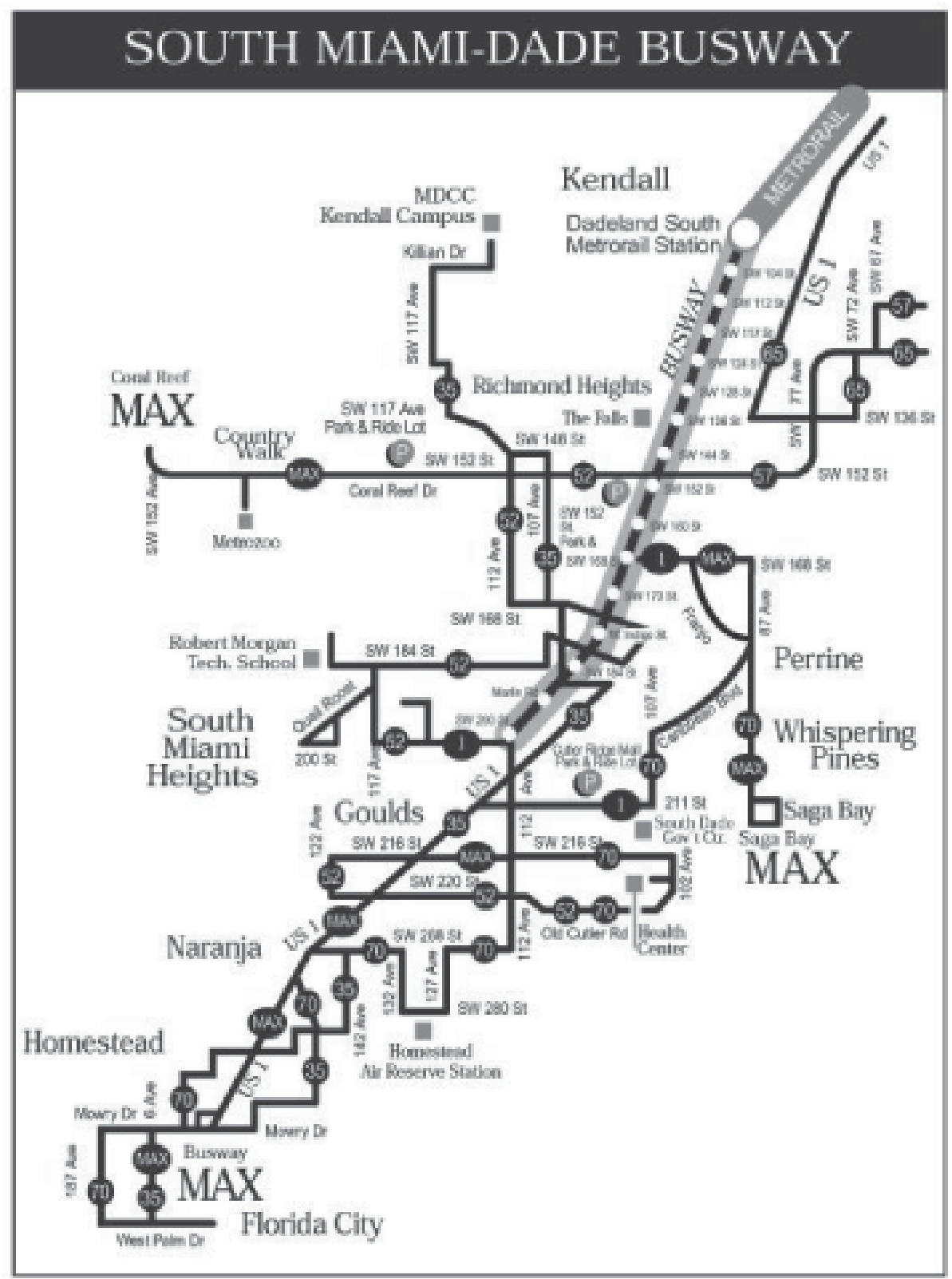


The Busway stations are located at roughly half-mile intervals, more than twice the customary stop spacing for conventional MDT local bus service. For example, when Route 1 operated on US 1, it had 19 designated stops southbound and 23 northbound (on the portion of the route using US 1). When it was moved to the Busway, only 10 Busway stations served the same distance. Most stations are on the far side of intersections. In two locations there are mid-block stops to serve major generators. All stations have large shelters designed to protect customers from the weather. Stations platforms are in three lengths: 40 feet, 60 feet, and 80 feet. Busway vehicles operate parallel in a bidirectional manner with vehicular traffic operating separate from Busway vehicles.

According to MDT, bus ridership on the U.S. 1 corridor in South Miami-Dade County increased greatly with the implementation of the Busway service. As a result of Busway service, ridership in the corridor increased by 49 percent on weekdays, 69 percent on Sundays, and 130 percent on Saturdays since May 1998. MDT staff indicated that the major reasons for the increases in ridership were the increase in service provided, in terms of new areas served, more frequent service, and a greater span of service. Except for Saturdays, revenue miles increased even faster than boardings and operating costs increased at only half the rate of the increase in vehicle revenue miles-due to the use of 20-seat minibuses, which cost the MDTA $\$ 31$ to $\$ 35$ per hour to operate, significantly less than the $\$ 51$ to $\$ 53$ per hour it costs to operate full-size buses. The difference in cost is due to fuel and maintenance costs and to the lower wages paid to minibus operators.

\section{Orlando LYMMO}

The LYMMO BRT system is very different in application from the Busway operated by MDT. It operates on a 3-mile continuous loop through Downtown Orlando using a combination of the various types of dedicated running ways including median and same-side travel way configurations. The exclusive running ways are paved with distinctive gray-colored pavers to delineate them from general traffic lanes. They are separated from general traffic lanes either with a raised median or a double row of raised reflective ceramic pavement markers embedded in the asphalt.

Because the LYMMO operates in places and directions contrary to other traffic, all bus movements at intersections are controlled by special bus signals. To prevent motorist confusion, these signal heads use lines instead of the standard red, yellow, and green lights. When a LYMMO bus approaches an intersection, an em- 
Figure 2. Map of the LYMMO System

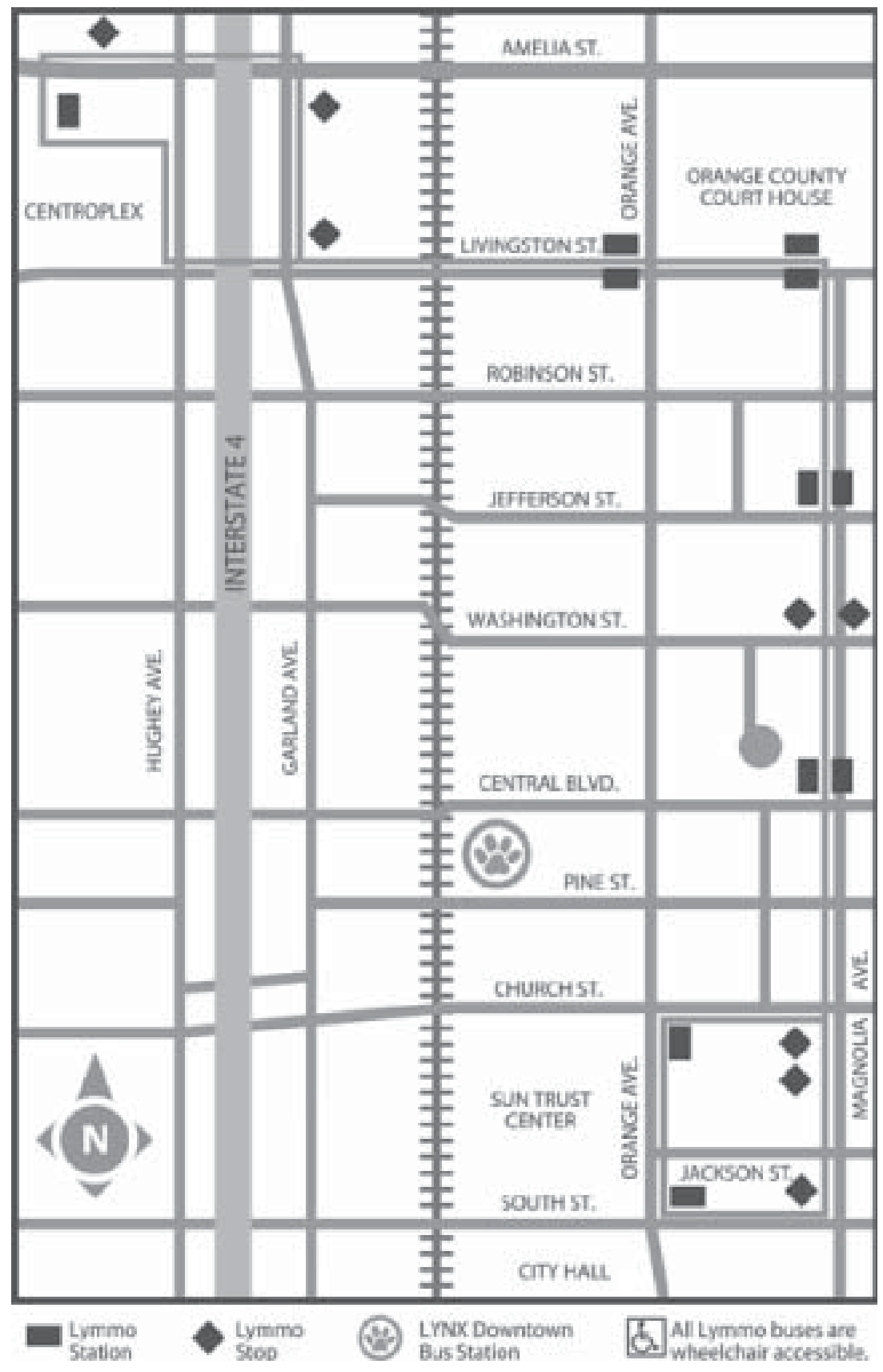


bedded loop detector in the dedicated running way triggers the intersection to allow the bus to proceed either in its own signal phase or at the same time as other traffic is released when no conflicting traffic movements are permitted.

The LYMMO uses 10 low-floor vehicles fueled by environmentally friendly compressed natural gas. The vehicles use high-quality, modern interiors that incorporate the Transit TV Network, an ITS system. The Transit TV Network provides realtime information such as Downtown events, weather, and fun and trivia to customers. In addition, public art exteriors are used on the vehicles to enhance the customer's experience with the LYMMO. The LYMMO system has 11 lighted and computerized stations and 9 additional stops, as shown in Figure 2.

LYMMO vehicles operate approximately every 5 minutes during office hours; after office hours, vehicles operate approximately every 10 minutes. Since the inception of service, the LYMMO has been free to ride during all hours of operation. Operation and maintenance of the LYMMO is 100 percent funded by revenue generated by the City of Orlando's Parking and Enterprise Fund. The LYMMO operates from 6 A.M. to 10 P.M., Monday through Thursday, 6 A.M. to midnight on Friday, 10 A.M. to midnight on Saturday, and 10 A.M. to 10 P.M. on Sunday. LYMMO's target market is customers who drive to Downtown Orlando and then use LYMMO to get to other Downtown locations, such as the courthouse, restaurants, shopping, and other land uses.

For comparison, Table 1 shows the key components of the both the Busway and LYMMO BRT systems.

\section{Survey Methodology and Statistical Procedures}

The Busway survey instrument was printed in English on one side and Spanish on the other due to the bilingual nature of Miami. It contained 18 questions and provided space for additional written comments by customers. The LYMMO survey instrument was printed in English only and contained a total 13 questions. $\mathrm{NBRTI} / \mathrm{CUTR}$ and MDT and Lynx staff developed the survey instruments jointly.

The on-board surveys specifically targeted customers riding only those routes that operate along the Busway for either all or a portion of their trips and for all or a portion of their trips in Downtown Orlando on the LYMMO. At least half of all trips on a particular Busway route were selected for surveying. For example, if there were eight trips on a route, four were to be surveyed. If there were nine trips, five were surveyed. The trips selected for survey distribution spanned the service 
Table 1. Key Bus Rapid Transit Components

\begin{tabular}{|c|c|c|c|c|}
\hline \multirow{2}{*}{ Key BRT Attributes } & \multicolumn{2}{|c|}{ Busway } & \multicolumn{2}{|c|}{ LYMMO } \\
\hline & Yes & No & Yes & No \\
\hline Simple route structure & $\boldsymbol{V}$ & & $\checkmark$ & \\
\hline Frequent service & $\checkmark$ & & $\checkmark$ & \\
\hline Headway-based schedules & $\checkmark$ & & $\boldsymbol{\sim}$ & \\
\hline Less frequent stops & $\checkmark$ & & $\checkmark$ & \\
\hline Level boarding and alighting & & $\checkmark$ & $\checkmark$ & \\
\hline Color-coded buses & & $\checkmark$ & & $\checkmark$ \\
\hline Color-coded stations/stops & $\boldsymbol{V}$ & & $\checkmark$ & \\
\hline Bus signal priority & & $\checkmark$ & $\checkmark$ & \\
\hline Exclusive lanes & $\checkmark$ & & $\checkmark$ & \\
\hline Modern vehicle interiors & & $\checkmark$ & $\boldsymbol{\sim}$ & \\
\hline Higher-capacity buses & & $\boldsymbol{\sim}$ & & $\checkmark$ \\
\hline Multiple door boarding and alighting & & $\boldsymbol{V}$ & $\checkmark$ & \\
\hline Off-vehicle fare payment & & $\checkmark$ & & $\checkmark$ \\
\hline Feeder network & $\checkmark$ & & & $\checkmark$ \\
\hline ITS/APTS on vehicles & $\checkmark$ & & $\checkmark$ & \\
\hline ITS/APTS at stations & & $\checkmark$ & $\checkmark$ & \\
\hline Coordinated land-use planning & $\checkmark$ & & $\checkmark$ & \\
\hline
\end{tabular}

hours (i.e., morning peak, midday off-peak, afternoon peak, and evening). For the LYMMO, surveying began at the start of service and concluded at about 7 P.M. Given that the typical weekday LYMMO schedule consists of about 18621-minute round trips (circulations) and the last trip begins at 10 P.M., this translates into just over 90 percent of all weekday trips being included in the sample.

Surveyors were instructed to offer a survey form to each customer upon boarding a bus. Every time a customer boarded a Busway or LYMMO vehicle to make a subsequent trip (regardless of the whether the trip was their second, third, fourth, and so on), they were asked to complete another survey. Surveyors were instructed to do the best they could to encourage participation in the survey. If a survey could not be handed directly to a customer, surveyors were instructed to "drop" a survey in each vehicle seat. All surveys were collected on-board buses. No mailback provision was provided for returning the completed surveys. 
Once collected, survey data were entered into an Excel spreadsheet for archiving and later analyses. CUTR staff performed the review and data analyses using SPSS (Statistical Product and Service Solutions) software.

Prior to the analyses, survey responses were weighted based on the total weekday ridership and completed surveys for each route to more accurately reflect Busway and LYMMO ridership as a whole. Weighting factors were derived to ensure proper representation of Busway and LYMMO customers. Specifically, weights were calculated by dividing the total weekday ridership (obtained from MDT and Lynx staff) for the survey period by the number of surveys returned. The resulting weight factors were applied to each completed survey's data for statistical analysis. The survey methodologies involved the survey of willing customers. The methodologies correspond most closely with ridership data that are reported as unlinked trips. Table 2 indicates Busway ridership figures for March 19-23, 2001 and Table 3 shows ridership for the LYMMO for December 20, 2001. The data in Table 2 are representative of the five-day (Monday through Friday) total weekday ridership and the data in Table 3 represent monthly LYMMO patronage. Daily ridership figures were not available for either of the two BRT systems.

Table 2. Weekday Busway Ridership (March 19-23, 2001)

\begin{tabular}{|l|c|c|}
\hline \multicolumn{1}{|c|}{ Entire Route } & Weekday Ridership* & $\begin{array}{c}\text { Percent of Ridership on Trips } \\
\text { Surveyed }\end{array}$ \\
\hline $\mathbf{1}$ & 8,182 & 17.4 \\
$\mathbf{3 1 / 2 3 1}$ (Busway Local) & 8,820 & 18.8 \\
$\mathbf{3 8}$ (Busway MAX) & 17,368 & 37.0 \\
$\mathbf{5 2}$ & 6,619 & 14.1 \\
$\mathbf{2 5 2}$ (Coral Reef MAX) & 4,491 & 9.6 \\
$\mathbf{2 8 7}$ (Saga Bay MAX) & $\mathbf{1 , 4 9 1}$ & 3.2 \\
Total Busway routes ridership & $\mathbf{4 6 , 9 7 1}$ & $\mathbf{1 0 0}$ \\
\hline
\end{tabular}

\footnotetext{
* Total weekday ridership for the entire route length.
} 
Table 3. Monthly LYMMO Ridership (December 2001)

\begin{tabular}{|l|c|c|}
\hline Week(Saturdaythrough Friday) & Ridership & $\begin{array}{c}\text { Proportion of Ridership on Trips } \\
\text { Surveyed }\end{array}$ \\
\hline December 1-7 & 20,618 & 27.8 \\
December 8-14 & 20,592 & 27.8 \\
December 15-21 & 19,992 & 27.0 \\
December 22-28 & 10,304 & 13.9 \\
December 29-31 & 2,541 & 3.4 \\
Total ridership & $\mathbf{7 4 , 0 4 7}$ & $\mathbf{1 0 0}$ \\
\hline
\end{tabular}

The response rates for the on-board surveys of Busway and LYMMO customers ranged from a low of 6.45 percent to 23.7 percent. Although somewhat low, these response rates are fairly usual for surveys of this type where prior experience has shown them to be in the 10 to 20 percent response range. It should be noted that the following results are based on a sample of system users and not a 100 percent census. There is the chance of some customers not choosing these two BRT systems because they felt that additional factors not discussed in the results were more important to their selection of mode choice. In addition, survey instruments were not originally designed to ask customers of these two BRT systems about their satisfaction with the Busway and LYMMO compared to other alternatives such as standard local bus. For example, the Busway survey could have included a question asking respondents to indicate their satisfaction with the travel time on Busway buses versus the travel time on standard local Miami-Dade Transit bus service. Everyone has a different approach to determining satisfaction with the various components that comprise a particular mode including travel time and frequency of service, for example. It is only when customers are asked to directly compare the various BRT components to those of other modes that comparable results can be obtained. Nevertheless, the results presented in this article show the measurement of actual customer satisfaction with the two BRT systems. Currently, there are many BRT systems in the planning and design phases as well as in operation that will benefit from the results presented in this article. 


\section{Measuring the Importance of BRT Elements Mean Scores}

Questions 17 (Busway) and 13 (LYMMO) on the survey instruments were multipart questions that asked customers to rate their perception of different aspects of Busway and LYMMO BRT services, using five-point scales ( 1 = "very dissatisfied" and $5=$ "very satisfied"). Each survey included a question that asked about overall customer satisfaction with the BRT services offered by both systems.

These two questions offered customers an opportunity to rate their individual levels of satisfaction with various service characteristics. Using the five-point rating system's numerical scoring values, an average score was calculated for each service characteristic. The resulting mean scores give a good indication of overall customer satisfaction with each of the service aspects. Since a score of 5 indicates a "very satisfied" rating, the closer to 5 that a characteristic's mean score is, the higher the degree of customer satisfaction is with that particular characteristic.

Table 4 presents all of the weighted average customer satisfaction ratings for the service characteristics included in the surveys. The responses indicate a very high level of satisfaction with the services offered by the Busway and LYMMO; all mean scores fell between "neutral" and "very satisfied," including the aspects travel time and reliability. An analysis of the very high customer mean scores and importance of the service attributes inquired about clearly shows that users regard the Busway and LYMMO BRT systems as premium services.

\section{STEPWISE Regression}

The simplest way to measure the importance that customers of public transit place on specific service characteristics is to calculate mean scores for each characteristic on some type of numeric scale (e.g., a scale of 1 through 5). While there are no real discernable drawbacks to this simple method, an alternate and more advanced technique to measure the importance of each service attribute is to derive importance by examining the relationship of each attribute to overall customer satisfaction. This methodology uses STEPWISE regression analysis to estimate the importance of each service attribute. While there is a degree of intercorrelation between each of the service attributes, this method can be used to measure the relative importance of each attribute when determining what elements or combination of elements comprise overall customer satisfaction of these two BRT systems. By using STEWISE regression, the r-squared values can be used as surrogates for customer satisfaction. 
Table 4. Means Satisfaction Scores for Busway and LYMMO

\begin{tabular}{|l|c|c|}
\hline \multirow{2}{*}{ Characteristics } & \multicolumn{2}{|c|}{ Mean Score } \\
\cline { 2 - 3 } & Busway & LYMMO \\
\hline Safety on bus & 3.81 & 4.41 \\
Availability of seats on the bus/comfort & 3.60 & 4.41 \\
Dependability of buses (headway adherence) & 3.18 & 4.47 \\
Travel time on buses & 3.63 & 4.48 \\
Cost of riding buses & 3.76 & Not asked \\
Availability of information/maps & 3.69 & Not asked \\
Convenience of routes & 3.69 & Not asked \\
Satisfaction with recent changes to Busway & 3.68 & Not asked \\
(traffic signals) & & Not asked \\
Safety at Busway stops & 3.65 & Not asked \\
Hours of Busway service & 3.50 & Not asked \\
Frequency of Busway service & 3.25 & \\
\hline
\end{tabular}

The STEPWISE regression analysis enters independent factors (each BRT service characteristic) one at a time, backwards and forwards, to determine which one has the highest correlation with the dependent factor (in this case, overall customer satisfaction). Additional independent factors are entered into the regression equation only when they make a significant contribution to the predictive power of the equation. During the process, if any of the independent factors falls below the specified criterion, it is removed automatically from the equation building process. In this case, the criterion for entering the regression equation was $p<$ 0.05 , and the criterion for removal from the regression equation was $p>0.10$. The STEPWISE regression analysis resulted in all four of the service characteristics entering the regression equation, accounting for 69.3 percent of the customers' overall satisfaction with the LYMMO service. For the Busway, the STEPWISE regression analysis resulted in all eight of the service characteristics entering the regression equation, accounting for 67.3 percent of the customers' overall satisfaction with 
Table 5. Results from LYMMO Customer Satisfaction STEPWISE Analysis

\begin{tabular}{|c|l|c|c|c|c|}
\hline $\begin{array}{c}\text { Model } \\
\text { Depend. } \\
\text { Variable }\end{array}$ & \multicolumn{1}{|c|}{$\begin{array}{c}\text { Model Independent } \\
\text { Variables }\end{array}$} & $\boldsymbol{R}$ & $\boldsymbol{R}$-Square & $\begin{array}{c}\text { Adjusted } \\
\boldsymbol{R} \text {-Square }\end{array}$ & $\begin{array}{c}\text { Std. Error of } \\
\text { the Estimate }\end{array}$ \\
\hline \multirow{2}{*}{$\begin{array}{c}\text { overall } \\
\text { customer } \\
\text { satisfaction }\end{array}$} & Comfort & 0.750 & 0.563 & 0.563 & 0.473 \\
& Comfort + Travel Time & 0.810 & 0.656 & 0.656 & 0.419 \\
& Reliability of Service & 0.830 & 0.689 & 0.689 & 0.399 \\
& Comfort + Travel Time + & 0.832 & 0.692 & 0.693 & 0.396 \\
\hline
\end{tabular}

Table 6. Results from Busway Customer Satisfaction STEPWISE Analysis

\begin{tabular}{|c|c|c|c|c|c|}
\hline $\begin{array}{l}\text { Model } \\
\text { Depend. } \\
\text { Variable }\end{array}$ & $\begin{array}{l}\text { Model/Service } \\
\text { Characteristics }\end{array}$ & $\boldsymbol{R}$ & R-Square & $\begin{array}{l}\text { Adjusted } \\
\text { R-Square }\end{array}$ & $\begin{array}{l}\text { Std. Error of } \\
\text { the Estimate }\end{array}$ \\
\hline $\begin{array}{c}\text { overall } \\
\text { customer } \\
\text { satisfaction }\end{array}$ & $\begin{array}{l}\text { Frequency of Service } \\
\text { Frequency of Service + } \\
\text { Convenience } \\
\text { Frequency of Service }+ \\
\text { Travel Time + Seat Availability } \\
\text { Frequency of Service + } \\
\text { Travel Time + Seat Availability } \\
+ \text { Convenience } \\
\text { Frequency of Service + } \\
\text { Travel Time + Seat Availability } \\
+ \text { Convenience + Hrs of Service } \\
\text { Frequency of Service + } \\
\text { Travel Time + Seat Availability } \\
+ \text { Convenience + Hrs of Service } \\
+ \text { Safety on Bus } \\
\text { Frequency of Service + } \\
\text { Travel Time + Seat Availability } \\
+ \text { Convenience }+ \text { Hrs of Service } \\
+ \text { Safety on Bus + Dependability } \\
\text { Frequency of Service + } \\
\text { Travel Time + Seat Availability } \\
+ \text { Convenience + Hrs of Service } \\
+ \text { Safety on Bus + Dependability }\end{array}$ & $\begin{array}{l}0.694 \\
0.771 \\
0.792 \\
0.805 \\
0.814 \\
0.818 \\
0.821 \\
0.823\end{array}$ & $\begin{array}{l}0.481 \\
0.594 \\
0.628 \\
0.649 \\
0.662 \\
0.669 \\
0.674 \\
\end{array}$ & $\begin{array}{l}0.480 \\
0.593 \\
0.627 \\
0.647 \\
0.660 \\
0.667 \\
0.671\end{array}$ & $\begin{array}{l}0.734 \\
0.649 \\
0.622 \\
0.605\end{array}$ \\
\hline
\end{tabular}


Busway service. Or, put another way, these service characteristics aided in understanding between almost 64 and 70 percent of overall customer satisfaction with the Busway and LYMMO services, as shown in Tables 5 and 6.

\section{Busway}

For the Busway, the first three-service characteristic to enter the regression equation were "frequency of service," "travel time," and "seat availability" (comfort). These three independent variables accounted for 62.7 percent of the equations overall predictive power, or overall customer satisfaction with the Busway. This finding is not surprising given the results for the simple mean scores for these service aspects where Busway customers rated each highly given the more "rapid" (real or perceived) nature of Busway service compared to MDT local service. Each of these service aspects (independent variables) is an important element of BRT service. The remaining service aspects to enter into the Busway STEPWISE regression model were, in order of entry, "convenience of routes," "hours of service," "safety on Busway vehicles," dependability (on-time performance), and the availability of route information. These remaining five variables added only 4.6 percent to the models overall predictive power. All of the service characteristics are significant at the $p<0.05$ level.

However, one important Busway service characteristic, "cost of riding the bus," did not enter into the regression equation as originally hypothesized. This result is counterintuitive to what is assumed about the factors that customers weigh in their decision to use local bus service. However, with a premium service such as that offered by a BRT system, it appears that cost is less of a concern than the overall quality of the BRT service and travel timesavings offered to customers. By its omission in the regression model, the data seem to indicate that if high quality premium service is offered, persons are willing to pay a little extra for the additional benefits of such a system.

The first service characteristic to enter the regression equation was "comfort of the LYMMO vehicles," accounting for 56.3 percent of the equations overall predictive power. This result is not surprising given that customers indicated that they liked the low-floor vehicles and modern vehicle interiors the most, each of these an important "comfort" element and aspect of BRT service. The second service characteristic to enter the regression equation was "travel time on LYMMO vehicles." The entry of "travel time" into the 
regression equation increased its overall predictive power to 65.6 percent, a significant increase in predictive power. Again, this result is not too surprising given that LYMMO customers indicated that they elected to use the LYMMO service because it is faster than walking to their destination. This finding is consistent with the "rapid" or "perceived rapid" nature of BRT services such as the LYMMO. The third variable to enter the regression equation was "reliability of LYMMO service." Interestingly, this service characteristic only marginally increased the overall predictive power of the regression model. This result is somewhat hard to explain, given that customers of public transit systems typically put a high premium on vehicle reliability that includes both on-time performance and vehicle breakdowns. The same holds true for the final service characteristic, "safety on vehicles," that entered into the regression equation. This service characteristic increased the predictive or explanatory power of the overall regression equation by only 0.004 percent. All of the service characteristics are significant at the $p<0.05$ level.

\section{Discussion and Conclusions}

Based on the results of the STEPWISE regression analysis, it appears that an argument could be made for a narrow and comprehensive set of traits as the basis for defining and providing different applications of BRT service. Based on the idea of providing a premium service that is more comfortable, frequent, rapid, and reliable than "typical" local bus service or other modes, BRT could be treated as an attempt to inject new energy and life into stagnant local transit bus services. Building on the results from this analysis, the unique services aspects of BRT that can be added to improve other bus services is good for all concerned.

Much discussion of late in the transit industry has been made about how to make BRT distinct and different from standard local service within an individual transit system. The answer may be found not in the type of vehicles that are provided to riders, but found mainly in the quality of BRT service that is ultimately offered. One only has to look at the success (increased ridership, decreased travel times) of the different BRT applications in Los Angeles; Pittsburgh; Ottawa, Canada; Brisbane, Australia; and Curitiba, Brazil to see the virtue of this statement. All of these BRT systems provide extremely frequent, reliable, easy to use, comfortable, safe, and fast (rapid) service (even in mixed traffic) essentially using conventional-looking buses. The results from the STEPWISE regression analysis seem to suggest that these systems are providing the right mix of service aspects to foster sustained patronage and growth. Perhaps what the customer really wants is to get from 
home to work and back again in the shortest time with the greatest overall level of comfort and personal safety (and to a degree, the cost of riding may not be an overriding factor). The results from this article suggest that future customers will rely more on the quality of the BRT service that's offered than any other aspect. Again, the success in terms of ridership gains and public acceptance of the Busway and LYMMO provide ample evidence to support this suggestion.

Based on MDT analysis, the Busway seems to have provided little or no travel timesavings for Busway vehicles compared to existing local service-yet, ridership in the corridor increased by 49 percent on weekdays, 69 percent on Sundays, and 130 percent on Saturdays since May 1998. This increase is mostly explained by the 72 percent increase in weekly revenue miles. This suggests that the MDT management did a good job of listening to customers when deploying and implementing Busway service. The combination of Busway service characteristics including high frequency, both in the peak and off-peak, travel time (real or perceived), and seat availability (comfort) are clearly central factors leading to this success.

Lynx reports that despite exclusive running ways and signal preemption, average roundtrip speeds are not as great as expected and are one-third slower on the LYMMO than its downtown predecessor the FreeBee. The reasons for this are hard to discern. One possible explanation is that LYMMO buses stop at each station, whether customers are waiting or not. Another possibility is that increased ridership has resulted in additional station dwell time during the boarding and alighting process-despite the use of low-floor vehicles and no fare collection. Despite the slow average system speed, LYMMO ridership has increased dramatically since system implementation-the real measure of success. Additional possible sources for increased ridership other than increased service hours is the creation of an overall pleasant and safe riding experience, an aggressive marketing campaign, comfort of the LYMMO vehicles, travel time (whether real or perceived) of LYMMO vehicles, reliability of LYMMO service, and safety on LYMMO vehicles and at stations.

Every customer of public transit has a different approach to determining their satisfaction with the various components that comprise a particular mode including travel time and frequency of service, for example, and their decision to use that mode at any given time. There is a chance that factors not present in the two BRT systems analyzed in this article could have caused customers not to choice the BRT mode for their trip making. For example, the Transit Cooperative Research Program (TCRP) Report 47 (1999) offers many different potential mea- 
sures of transit service quality including overcrowding, bilingual signage and system information, quietness of vehicles, fairness of fare structure, announcements of delays, cost of making transfers, absence of offensive odors, ease of paying fare, number of transfer points outside of the downtown core, courteous system staff, physical condition of stations, station access, posted minutes to next bus, and so on in addition to the factors presented in this article. The survey instruments used to gather information for this article were not originally designed to ask customers about every possible service characteristic related to the Busway and LYMMO. Nevertheless, the results presented here show the measurement of actual customer satisfaction with important service characteristics of the two BRT systems and those elements that are important to all BRT systems. At present, there are many BRT systems in the planning and design phases as well as in operation that will benefit from the results presented in this article even using a limited number of service quality measures to determine overall customer satisfaction.

Although the $\mathrm{R}^{2}$-values are fairly high even with the small number of independent factors ( 4 for the LYMMO and 10 for the Busway), it is important to note that about 33 percent of with the Busway and 31 percent with the LYMMO service related to overall customer satisfaction remains unexplained. As part of the BRT evaluation processes, a number of focus groups will be conducted that could aid in uncovering the remaining factors related to overall customer satisfaction. Certainly, the four service characteristics included in the regression equation make it clear that they are important factors to customers of this BRT system. However, the unexplained variance also makes it clear that a full understanding behind the dynamics of customer satisfaction may require the inclusion of additional independent variables in futures regression analyses as noted in the preceding paragraph. These service characteristics would certainly include those present in other BRT systems or perhaps psychological factors related to customer satisfaction.

While BRT is the talk of the U.S. public transit industry (and even the global transit industry), there is still a long way to go to make this a successful and publicly accepted mode of public transportation as in other places including Canada, South America, Australia, and Europe. There is a continued need for marketing, vehicle development, data collection, project evaluation, an updated Alternatives Analysis process to include BRT, revised New Starts eligibility criteria, research, and additional technology transfer. The author supports the statements made by the FTA that no single mode of public transportation is right for all situations. How- 
ever, given the incontestable merits of BRT, it should receive serious consideration as an important alternative in the planning toolkit.

\section{References}

Schwenk, J.C. 2002. Evaluation guidelines for Bus Rapid Transit Demonstration Projects. DOT-VNTSC-FTA-02-02, DOT-MA-26-7033-02. February.

Transit Cooperative Research Program. 1999. TCRP Report 47-A handbook for measuring customer satisfaction and service quality. Washington D.C.: Transportation Research Board, National Research Council.

Los Angeles County Metropolitan Transportation Authority. Metro Rapid Evaluation Before and After Survey Results. Unpublished paper, date unknown.

Henke, Cliff. A Practical Approach to Bus Rapid Transit. Unpublished paper. North American Bus Industries, Woodland Hills, CA, 2002.

U.S. General Accounting Office. Bus Rapid Transit Shows Promise. September 2001.

Levinson, Herbert S. et al., Bus Rapid Transit Synthesis of Case Studies. Presented at the Annual Meeting of the 2003 Transportation Research Board and scheduled for publication in an upcoming Transportation Research Record.

\section{About the Author}

Michael R. Baltes (baltes@cutr.usf.edu) is a senior research associate at the National Bus Rapid Transit Institute (NBRTI) located at the Center for Urban Transportation Research in Tampa, Florida. He has worked at the Center for Urban Transportation Research for 12 years. During his tenure at the center, he has gained extensive experience in the areas of Bus Rapid Transit (BRT), transit planning, transportation economics, Intelligent Transportation Systems, and a variety of other transportation research areas. Mr. Baltes holds both graduate and undergraduate degrees from the University of South Florida. He is an active member in a number of professional organizations, and is regularly cited and published in academia and media on BRT and other transportation issues. He is also a member of the Transportation Research Board Committee on Bicycle Transportation and the American Public Transportation Association's BRT Task Force. 